\title{
A Case of Euglycemic Diabetic Ketoacidosis in a Patient With Type 2 Diabetes Mellitus and COVID-19
}

\author{
Nathan Morrison ${ }^{1}$, Katherine Barnett ${ }^{1}$, Julianna Tantum ${ }^{2}$, Hannah K. Morrison ${ }^{3}$, Michael Whalen ${ }^{3}$ \\ 1. Internal Medicine, Philadelphia College of Osteopathic Medicine, Philadelphia, USA 2. Internal Medicine, Lankenau \\ Medical Center, Wynnewood, USA 3. Emergency Medicine, Lankenau Medical Center, Wynnewood, USA
}

Corresponding author: Hannah K. Morrison, brenemanh@mlhs.org

\begin{abstract}
Diabetic ketoacidosis (DKA) can cause significant morbidity and mortality in patients with type 1 or type 2 diabetes mellitus. DKA causes an approximate annual hospitalization rate of $6.3 \%$ and in-hospital casefatality rate of $0.4 \%$. A subset of DKA cases termed euglycemic diabetic ketoacidosis (eu-DKA) is characterized by euglycemia ( $<200 \mathrm{mg} / \mathrm{dL}$ ), high anion gap metabolic acidosis, and an increased plasma ketone concentration. This clinical syndrome comprises approximately $2.6 \%$ to $3.2 \%$ of total DKA admissions, making it a rare condition. In this case report, a male patient was diagnosed with coronavirus disease 2019 (COVID-19) three days prior to arriving at the emergency department. Upon evaluation, he displayed severe acidemia and was diagnosed with eu-DKA. He was started on intravenous regular insulin and D5 one-half normal saline, which markedly improved his metabolic status. Notably, his admission was uncomplicated by respiratory symptoms of COVID-19. It is proposed that his eu-DKA was catalyzed by his recent COVID-19 infection. Recent studies that have shown COVID-19 may increase lipolysis and induce ketogenesis in susceptible patients.
\end{abstract}

Review began $11 / 24 / 2020$ Review ended 11/30/2020 Published 12/11/2020

๑) Copyright 2020 Morrison et al. This is an open access article distributed under the terms of the Creative Commons Attribution License CC-BY 4.0., which permits unrestricted use, distribution, and reproduction in any medium, provided the original author and source are credited.
Categories: Endocrinology/Diabetes/Metabolism, Emergency Medicine, Internal Medicine Keywords: covid 19, medical intensive care unit, sars-cov-2, euglycemic dka, diabetic ketoacidosis (dka), emergency department, diabetes mellitus type 2

\section{Introduction}

The Centers for Disease Control and Prevention (CDC) has indicated that adults with type 2 diabetes mellitus (T2DM) are at an increased risk of severe morbidity and mortality with coronavirus disease 2019 (COVID-19) infections [1]. A life-threatening complication of diabetes, known as diabetic ketoacidosis (DKA), causes an approximate annual hospitalization rate of $6.3 \%$ and in-hospital case-fatality rate of $0.4 \%$ [2]. DKA is characterized by a triad including uncontrolled hyperglycemia ( $>250 \mathrm{mg} / \mathrm{dL})$, high anion gap metabolic acidosis, and an increased plasma ketone concentration. However, DKA can rarely occur with a normal blood glucose level ( $<200 \mathrm{mg} / \mathrm{dL}$ ), which is termed euglycemic DKA (eu-DKA). An estimated $2.6 \%$ to $3.2 \%$ of DKA admissions are eu-DKA cases [3-5]. This case report reviews the hospital course of a patient who presented to the emergency department (ED) with eu-DKA and severe acidemia in the setting of a known COVID-19 infection for three days. The patient was also treated for his T2DM with an sodiumglucose cotransporter 2 (SGLT2) inhibitor. The rare incidence of eu-DKA causes the possibility of misdiagnosis in patients, and the need for increased awareness in the midst of the COVID-19 pandemic. A recent study by Li et al. recognized COVID-19 as a possible cause of ketosis and ketoacidosis in susceptible patients [6].

\section{Case Presentation}

A male in his 40s with a past medical history of T2DM and hyperlipidemia was diagnosed with COVID-19 three days prior to presentation to the ED. The patient came for the evaluation of worsening symptoms of fatigue, non-productive cough, and poor appetite for six days. He also admitted to several episodes of nonbloody, non-bilious vomiting, and poor oral intake. When questioned, he reported compliance with his home medications including $25 \mathrm{mg}$ of empagliflozin daily, $3 \mathrm{mg}$ of semaglutide daily, $500 \mathrm{mg}$ of metformin twice per day, $40 \mathrm{mg}$ of atorvastatin daily, and $200 \mathrm{mg}$ of modafinil daily. On physical examination, significant findings showed that he was diaphoretic and actively vomiting. His vitals signs were significant for a heart rate of 113 beats per minute, temperature of $37.6^{\circ} \mathrm{C}\left(99.7^{\circ} \mathrm{F}\right)$, blood pressure of $122 / 95 \mathrm{~mm} \mathrm{Hg}$, 20 breaths per minute, and $97 \%$ oxygen saturation on room air. Comprehensive metabolic panel (CMP) results were notable for a serum sodium level of $133 \mathrm{mEq} / \mathrm{L}$ (corrected sodium of $134 \mathrm{mEq} / \mathrm{L}$ ), carbon dioxide $11 \mathrm{mEq} / \mathrm{L}$, creatinine of $1.5 \mathrm{mg} / \mathrm{dL}$, glucose $177 \mathrm{mg} / \mathrm{dL}$, and calculated anion gap of $25 \mathrm{mEq} / \mathrm{L}$. Complete blood count (CBC) results were significant for a white blood cell count of $11.76 \times 10^{3} / \mu \mathrm{L}$ and red blood cell count of $20.4 \times 10^{6} / \mu \mathrm{L}$. Beta-hydroxybutyrate resulted in $8.62 \mathrm{mmol} / \mathrm{dL}$. Venous blood gas (VBG) determined a $\mathrm{pH}$ of 7.06, partial pressure of carbon dioxide of $37 \mathrm{~mm} \mathrm{Hg}$, partial pressure of oxygen of 31 $\mathrm{mm} \mathrm{Hg}$, bicarbonate level of $10.0 \mathrm{mEq} / \mathrm{L}$, and lactate $2.3 \mathrm{mmol} / \mathrm{L}$. Urinalysis was positive for glucose ( $\geqslant 1000$ $\mathrm{mg} / \mathrm{dL}$ ) and ketones (>80 mg/dL). Other non-specific laboratory results for active COVID-19 infection 


\section{Cureus}

revealed a lactate dehydrogenase level of $259 \mathrm{U} / \mathrm{L}$, ferritin $591 \mathrm{ng} / \mathrm{mL}$, creatine kinase $59 \mathrm{U} / \mathrm{L}$, and C-reactive protein level of $94.2 \mathrm{mg} / \mathrm{L}$. His chest $\mathrm{x}$-ray was negative for acute disease (Figure 1). Upon initial evaluation in the $\mathrm{ED}$, the patient was administered $2 \mathrm{~L}$ of normal saline, $4 \mathrm{mg}$ of intravenous ondansetron, and $20 \mathrm{mg}$ of intravenous famotidine. After laboratory evaluation and diagnosis of eu-DKA, he was started on continuous intravenous (IV) regular insulin at a rate of 1.5 units/hour and a continuous IV infusion of D5 one-half normal saline at a rate of $100 \mathrm{~mL} /$ hour. The patient was admitted to the medical ICU for further management of eu-DKA in the setting of active COVID-19 infection. The patient's hemoglobin A1c was determined to be $10.6 \%$ at admission. While in the ICU, the patient was continued on the same regimen of IV insulin and D5 one-half normal saline that was started earlier in the ED. His bicarbonate improved to $22 \mathrm{mEq} / \mathrm{L}$ and his anion gap normalized to $10 \mathrm{mEq} / \mathrm{L}$. He was transferred to the general medicine floor after three days, and his regimen was transitioned to 25 units of subcutaneous insulin glargine every night and 10 units of subcutaneous insulin lispro before meals, as recommended by endocrinology. Four days later, he was discharged home in a stable condition and instructed to follow up with endocrinology for his eu-DKA episode and T2DM management. Throughout his entire hospital admission, his COVID-19 respiratory symptoms remained fairly mild.

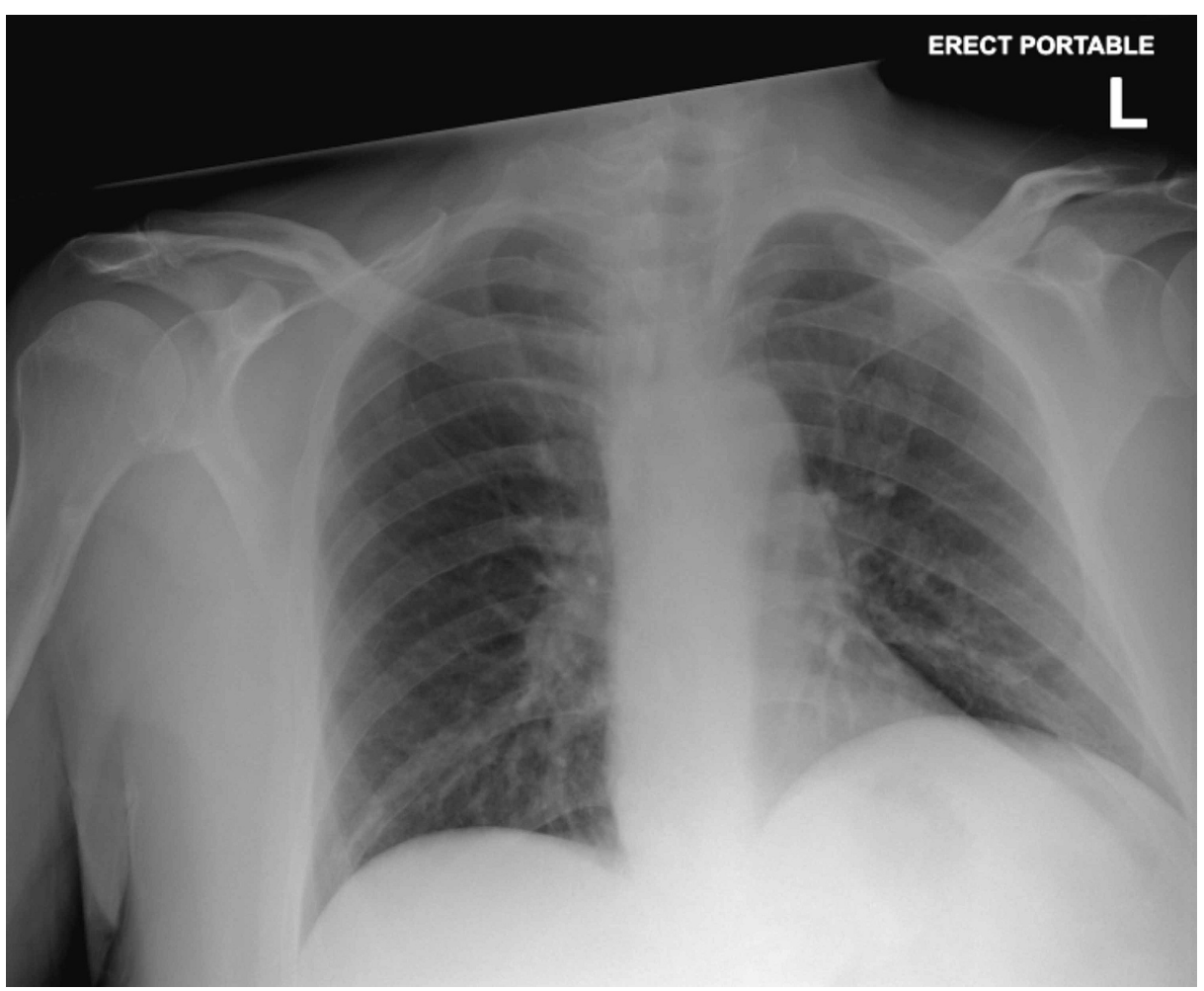

\section{FIGURE 1: A single anteroposterior view of the chest via chest $\mathrm{x}$-ray}

No acute disease is displayed. There are signs of degenerative changes in the shoulders.

\section{Discussion}

Adults with T2DM are at an increased risk of contracting severe illness and mortality with COVID-19 infections [1]. In this case, the patient presented to the ED with vomiting and a worsening non-productive cough. He was diagnosed with eu-DKA in the setting of a positive COVID-19 infection for three days.

There have been three other reported cases of patients with a history of diabetes that presented with euDKA in the setting of active COVID-19 infection. In one case, the patient had a history of type 1 diabetes mellitus (T1DM), and his admission was complicated by COVID-19 pneumonia and mechanical ventilation. This case did not report a measured serum $\mathrm{pH}$ [7]. In the second case, the patient had a history of T2DM, showed signs of COVID-19 pneumonia on imaging, had decreased oxygen saturation on room air, required high flow nasal cannula for eight days, and displayed moderate acidemia in the ICU $(\mathrm{pH}=7.28)$ [8]. The third case had a patient with a history of T2DM who also showed signs of COVID-19 pneumonia on imaging, resulting hypoxemic respiratory failure with intubation, and moderate acidemia $(\mathrm{pH}=7.24)$ [9].

To our knowledge, this is the only case of a patient with a medical history of T2DM treated with an SGLT2 inhibitor, a COVID-19 diagnosis, severe acidemia ( $\mathrm{pH} \leqslant 7.1)$, negative imaging, and no signs of respiratory compromise [7-11]. In this patient, it is proposed that the severe acidemia $(\mathrm{pH}=7.06)$ was exacerbated by his active COVID-19 infection, causing eu-DKA. A study by Li et al. suggested that COVID-19 may increase 
lipolysis and induce ketosis [6]. This finding suggested that patients with diabetes may be susceptible to DKA with active COVID-19 infections. Noticeably, interleukin-6 (IL-6) is found to be markedly elevated by COVID-19 and is related to its prognosis. IL- 6 is a proposed dynamic cause of ketone production through the induction of cellular insulin resistance in hepatocytes $[4,12-14]$. In this case, it is possible that the severe acidemia and eu-DKA were exacerbated by his COVID-19 symptoms that began six days earlier. Although SGLT- 2 inhibitors have been related to eu-DKA cases, it was determined a less likely precipitating etiology in this patient due to the recent infectious diagnosis. According to the Empagliflozin Cardiovascular Outcome Event Trial in Type 2 diabetes Mellitus Patients (EMPA-REG Outcome Trial), his use of empagliflozin is known to be an extremely rare cause of eu-DKA. It was found that cases of DKA related to the medication are around $0.1 \%$ [3-5]. It is also possible his empagliflozin therapy could have played a synergistic role with COVID-19 in his eu-DKA presentation through medication-induced glycosuria, decreasing his plasma glucose and increasing ketogenesis [4].

\section{Conclusions}

The rare presentation and prevalence of eu-DKA causes the possibility of misdiagnosis in patients, and the need for increased awareness in the center of the COVID-19 pandemic. Recent studies have recognized COVID-19 as a possible cause of ketosis and ketoacidosis in susceptible patients. Therefore, surveillance of diabetic patients for plausible eu-DKA should be warranted with a COVID-19 suspicion or diagnosis. The diagnosis eu-DKA may go unrecognized in susceptible patients if neglected in an acute care setting.

\section{Additional Information \\ Disclosures}

Human subjects: Consent was obtained by all participants in this study. Conflicts of interest: In compliance with the ICMJE uniform disclosure form, all authors declare the following: Payment/services info: All authors have declared that no financial support was received from any organization for the submitted work. Financial relationships: All authors have declared that they have no financial relationships at present or within the previous three years with any organizations that might have an interest in the submitted work. Other relationships: All authors have declared that there are no other relationships or activities that could appear to have influenced the submitted work.

\section{References}

1. Benoit SR, Zhang Y, Geiss LS, Gregg EW, Albright A: Trends in diabetic ketoacidosis hospitalizations and inhospital mortality - United States, 2000-2014. MMWR Morb Mortal Wkly Rep. 2018, 67:362-365. 10.15585/mmwr.mm6712a3

2. Vellanki P, Umpierrez GE: Increasing hospitalizations for DKA: a need for prevention programs . Diabetes Care. 2018, 41:1839-1841. 10.2337/dci18-0004

3. Plewa MC, Bryant M, King-Thiele R: Euglycemic diabetic ketoacidosis. In StatPearls [Internet]. StatPearls Publishing, Treasure Island, FL; 2020.

4. Rosenstock J, Ferrannini E: Euglycemic diabetic ketoacidosis: a predictable, detectable, and preventable safety concern with SGLT2 inhibitors. Diabetes Care. 2015, 38:1638-1642. 10.2337/dc15-1380

5. Zinman B, Lachin JM, Inzucchi SE: Empagliflozin, cardiovascular outcomes, and mortality in type 2 diabetes. N Engl J Med. 2016, 374:1092-1094. 10.1056/NEJMc1600827

6. Li J, Wang X, Chen J, Zuo X, Zhang H, Deng A: COVID-19 infection may cause ketosis and ketoacidosis. Diabetes Obes Metab. 2020, 22:1935-1941. 10.1111/dom.14057

7. Oriot P, Hermans MP: Euglycemic diabetic ketoacidosis in a patient with type 1 diabetes and SARS-CoV-2 pneumonia: case report and review of the literature. [Online ahead of print]. Acta Clin Belg. 2020, 1-5. 10.1080/17843286.2020.1780390

8. Batista DV, Vieira CAFA, Costa TA, Lima EG: COVID-19-associated euglycemic diabetic ketoacidosis in a patient with type 2 diabetes on SGLT2 inhibitor: a case report. [Online ahead of print]. Diabetol Int. 2020, 14. 10.1007/s13340-020-00473-3

9. Palermo NE, Sadhu AR, McDonnell ME: Diabetic ketoacidosis in COVID-19: unique concerns and considerations. J Clin Endocrinol Metab. 2020, 105:2819-2829. 10.1210/clinem/dgaa360

10. Guh JY, Lai YH, Yu LK, Shin SJ, Tsai JH: Evaluation of ventilatory responses in severe acidemia in diabetic ketoacidosis. Am J Nephrol. 1997, 17:36-41. 10.1159/000169069

11. Morris LR, Murphy MB, Kitabchi AE: Bicarbonate therapy in severe diabetic ketoacidosis . Ann Intern Med. 1986, 105:836-840. 10.7326/0003-4819-105-6-836

12. Karavanaki K, Karanika E, Georga S, et al.: Cytokine response to diabetic ketoacidosis (DKA) in children with type 1 diabetes (T1DM). Endocr J. 2011, 58:1045-1053. 10.1507/endocri.ej11-0024

13. Senn JJ, Klover PJ, Nowak IA, Mooney RA: Interleukin-6 induces cellular insulin resistance in hepatocytes . Diabetes. 2002, 51:3391-3399. 10.2337/diabetes.51.12.3391

14. Chen X, Zhao B, Qu Y, et al.: Detectable serum severe acute respiratory syndrome coronavirus 2 viral load (RNAemia) is closely correlated with drastically elevated interleukin 6 level in critically ill patients with coronavirus disease 2019. Clin Infect Dis. 2020, 71:1937-1942. 10.1093/cid/ciaa449 